\title{
Changes in Expression and Localization of GPRC5B and RAR $\alpha$ in the Placenta and Yolk Sac During Middle to Late Gestation in Mice
}

\author{
Satoshi IMANISHI ${ }^{1)}$, Miki SUGIMOTO' ${ }^{2)}$, Maki MORITA ${ }^{2)}$, Shinichi KUME ${ }^{2)}$ and \\ Noboru MANABE ${ }^{3)}$ \\ ${ }^{1)}$ Health Risk Research Section, Research Center for Environmental Risk, National Institute for \\ Environmental Studies, Tsukuba 305-8506, ${ }^{2)}$ Department of Animal Sciences, Kyoto \\ University, Kyoto 606-8502 and ${ }^{3)}$ Animal Resource Science Center, The University of Tokyo, \\ Ago 3145, Kasama 319-0206, Japan
}

\begin{abstract}
The mRNA expression of GPRC5B, an orphan G protein-coupled receptor, is induced by retinoic acid (RA). Because RA plays critical roles in embryonic development, reproductive functions, metabolism and homeostasis, GPRC5B is also considered crucial in these physiological events. We investigated the changes in expression of GPRC5B and $R A$ receptor (RAR) $\alpha$ mRNAs and immunohistochemical localization of their proteins in the murine placenta and yolk sac at 13.5, 15.5 and 17.5 days post coitus. Stable levels of GPRC5B and RAR $\alpha$ mRNAs were detected in the placenta and yolk sac. In the placenta, GPRC5B was present in maternal and fetal vascular endothelial cells, stromal cells, fibroblast-like cells and glycogen cells. A strong reaction to RAR $\alpha$ was detected in maternal and fetal vascular endothelial cells and stromal cells. The levels of GPRC5B and RAR $\alpha$ proteins in maternal and fetal vascular endothelial cells decreased with gestation. In the yolk sac, GPRC5B and RAR $\alpha$ proteins were detected in vascular endothelial cells, but their levels did not change during the gestation period. These findings indicate that GPRC5B is involved in RAdependent morphogenesis/angiogenesis and regulation of extracellular matrix synthesis in the murine placenta and yolk sac.

Key words: Angiogenesis, Mouse, Orphan G protein-coupled receptor (GPRC5B), Placenta, Retinoic acid receptor $\alpha(\operatorname{RAR} \alpha)$, Yolk sac
\end{abstract}

(J. Reprod. Dev. 53: 1131-1136, 2007)

G protein-coupled receptors (GPCRs) compose a large family characterized by seven transmembrane domains. Since their ligands are involved in a wide range of signaling pathways, such as in response to light, calcium cation, odorants, amino acids, nucleotides and peptides, they play essential roles in many physiological events. However, many GPCRs remain so-called orphan receptors,

Accepted for publication: June 15, 2007

Published online: July 23, 2007

Correspondence: N. Manabe

(e-mail. amanabe@mail.ecc.u-tokyo.ac.jp) whose ligands are unknown [1]. GPRC5B, an orphan GPCR [2, 3], contains transmembrane domains that have high homology with those of metabolic glutamate receptors (mGluRs) and is classified into family C. Family C contains mGluRs, calcium sensing receptors (CaRs), type B $\gamma$-aminobutyric acid receptors (GABA $\left.\mathrm{G}_{\mathrm{B}} \mathrm{R}\right)$, putative pheromone receptors (V2Rs), taste receptors (T1Rs) and Drosophila bride of sevenless (BOSS) [4]. GPRC5B belongs to the retinoic acid inducible gene (RAIG) group, which consists of at least 4 orphan receptors $[2,3,5]$. The $\mathrm{N}$-terminal extracelluler 
region of RAIG members is very short, although that region of other family $\mathrm{C}$ members is long. Because the N-terminal extracellular region forms a ligand-binding domain, named the venous fly trap, in the family $C$ receptor molecule [6], the ligands and signaling pathways of the RAIG family can be quite unique. Additionally, as the name suggests, the mRNA expression of all RAIG members is induced by stimulation with retinoic acid (RA) $[2,3$, $7,8]$, which plays crucial roles in many physiological events, such as embryonic development, reproduction, metabolism, and homeostasis $[9,10]$. Thus, RAIG members are considered essential to RA-dependent physiological events. However, little information is available concerning the physiological function of RAIG members, especially GPRC5B. In humans, high levels of GPRC5B mRNA have been reported in the central nervous system, kidney, pancreas and testis, moderate levels have been reported in the heart, prostate, small intestine, and spleen and low levels have been reported in the placenta and ovary [2]. The unique immunohistochemical distribution of GPRC5B in the rat central nervous system indicates crucial roles in neural signal transmission and memory. Moreover, strong expression of GPRC5B mRNA has been noted in the mouse placenta [11]. Stimulation with tumor necrosis factor (TNF)- $\alpha$ and transforming growth factor (TGF)- $\beta 1$ induces GPRC5B mRNA expression in porcine endothelial cells [12] and mesoangioblasts [13]. To date, we have obtained information on other RAIG members. For example, GPRC5A, also called RAIG1 or Rai3, is specifically expressed in the lungs and is considered a clinical target of breast cancer, although GPRC5 $\mathrm{A}^{-/-}$mice show normal pulmonary development $[14,15]$. GPRC5D increases keratin expression in vitro and in vivo [8].

Phylogenic analysis indicates that the ligands of the RAIG family may be small molecules [16]. Based on a cross-species phylogenic analysis, Drosophila BOSS, a ligand for sevenless tyrosine kinase type receptor $[4,17]$, is probably the closest to RAIGs [18]. However, the homology of these proteins is considered to be low. To date, over 1,000 candidates for ligands of RAIGs have been proposed, but no positive reaction has yet been detected [19].

RA, an active form of vitamin $A$, regulates gene expression through a complex of retinoic acid receptors (RARs) and retinoid $X$ receptors (RXRs).
Each RAR and RXR has 3 subtypes, $\alpha, \beta$ and $\gamma$ [20]. In the mouse placenta during late gestation, RAR $\alpha$ mRNA is ubiquitously expressed from 13.5 days post coitus (dpc) to $17.5 \mathrm{dpc}$, and RAR $\gamma$ mRNA is weakly expressed in the labyrinthine layer from 13.5 to $15.5 \mathrm{dpc}$; however, RAR $\beta$ mRNA is not detected [21]. In the mouse yolk sac, only RAR $\alpha$, which is essential for normal vasculogenesis and angiogenesis in the yolk sac [22], is detected [21]. GPRC5B may be involved in these retinoic acid morphogenic functions of retinoic acid in the placenta and yolk sac.

In the present study, we investigate the changes in the level of GPRC5B mRNA and distribution of GPRC5B in the mouse placenta and yolk sac during late gestation in order to acquire basic information on the physiological function of GPRC5B in vivo.

\section{Materials and Methods}

\section{Animals}

Male and female ICR mice purchased from Clea Japan (Tokyo, Japan) were housed in polycarbonate cages and maintained in a humidity $(30-40 \%)$ and temperature $(24 \pm 3 \mathrm{C})$ controlled room with a $14 \mathrm{~h}$ light-10 h dark cycle. All animals were given free access to tap water and rodent food (CM; Oriental Yeast, Tokyo, Japan) ad libitum. They received humane care as outlined in the "Guide for the Care and Use of Laboratory Animals" (Kyoto University Animal Care Committee according to NIH No. 8623; revised 1999). After mating for one night, females found to have a vaginal plug were considered to be at $0.5 \mathrm{dpc}$ of pregnancy. At 13.5, 15.5 and $17.5 \mathrm{dpc}$, the pregnant dams were sacrificed under anesthesia with diethyl ether in the afternoon (1200-1400 h). Placentas and yolk sacs were rapidly removed and washed in phosphate-buffered saline (PBS, $\mathrm{pH} 7.4$ ). For reverse transcriptionpolymerase chain reaction (RT-PCR), the tissues were rapidly frozen in liquid nitrogen and stored at $-80 \mathrm{C}$ until extraction of RNA. For immunohistochemical analysis, the tissues were fixed in neutral buffered $4 \%$ formaldehyde (Wako Pure Chemicals, Osaka, Japan).

\section{Semi-quantitative RT-PCR}

Total RNA was extracted from homogenized tissues using a RNeasy mini kit (Qiagen, Chatsworth, CA, USA). Complementary DNA (cDNA) was syn- 
thesized with an oligo(dT) primer using a Readyto-Go T primed first strand kit (Amersham Pharmacia Biotech, Piscataway, NJ, USA) from $2 \mu \mathrm{g}$ of RNA for each sample. The cDNA was quickchilled on to ice to denature the RNA-cDNA duplex. PCR was performed in a final volume of 50 $\mu$ l containing $45 \mu \mathrm{l}$ of Platinum PCR SuperMix (Invitrogen, Carlsbad, CA, USA), $1 \mu \mathrm{l}$ (100 ng) of each cDNA and $2 \mu \mathrm{l}(0.2 \mathrm{mM})$ of each primer. All procedures were performed according to each manufacturer's protocol. The primer pairs used for PCR were as follows: 5'-GAGTT CGAGT TCACC TGGAG AGG-3' and 5'-TCTCT CAGGA GAGGA CAGAG TGG-3' for GPRC5B mRNA, 5'-AGGCC ATCAC AACTA CCTGC-3' and 5'-GGAAA GAAGA AGGCG TAGGG-3' for RAR $\alpha$ mRNA and 5'-GGGTG GAGCC AAACG GGTC- 3' and 5'GGAGT TGCTG TTGAA GTCGC-3' for GAPDH mRNA. The PCR profiles for GPRC5B, RAR $\alpha$ and GAPDH were as follows: $94 \mathrm{C}$ for $5 \mathrm{~min}$ to denature the DNA; 35 cycles at $94 \mathrm{C}$ for $1 \mathrm{~min}, 59 \mathrm{C}$ for $1 \mathrm{~min}$, and $72 \mathrm{C}$ for $1 \mathrm{~min}$; and finally 1 cycle at $72 \mathrm{C}$ for 7 min. The PCR products were electrophoresed in a $2 \%(\mathrm{w} / \mathrm{v})$ agarose gel (Wako) and stained with a 1 $\mu \mathrm{g} / \mathrm{ml}$ ethidium bromide solution (Wako). A ready-load 100-bp DNA ladder (Invitrogen) was used as a molecular weight marker for electrophoresis. After electrophoresis, the gels were scanned with a digital recorder, and then mRNA expression levels were semiquantified using NIH Image. The relative abundance of specific mRNA was normalized to the abundance of GAPDH mRNA.

\section{Immunohistochemistry}

Tissues were embedded in paraffin, cut into sections $3 \mu \mathrm{m}$ thick and put on slide glass pre-coated with 3-aminopropyltriethoxysilane (Wako). The sections were deparaffinized, hydrated and treated with $0.5 \mathrm{M}$ citrate buffer ( $\mathrm{pH} \mathrm{6.0)}$ at $95 \mathrm{C}$ for $20 \mathrm{~min}$ for activation of the antigen. After washing in PBS, the endogenous peroxydase was inactivated by treatment with $3 \%(\mathrm{v} / \mathrm{v}) \mathrm{H}_{2} \mathrm{O}_{2}$ solution. The sections were pretreated with normal rabbit serum (Dako Cytomation, Carpinteria, CA, USA) and incubated with specific antibodies for each protein for $1 \mathrm{~h}$ at room temperature (20-25 C). The antibodies were anti-human GPRC5B rabbit polyclonal IgG antibody (SP4270P; Acris Antibodies GmbH, Hiddenhausen, Germany) diluted 1:100 and antihuman RAR $\alpha$ rabbit polyclonal IgG antibody (sc-
551; Santa Cruz Biotechnology, Santa Cruz, CA, USA) diluted 1:100. Subsequently, the sections were incubated with horse radish peroxydase-conjugated anti-rabbit IgG antibody (En Vision ${ }^{+}$ System; Dako Cytomation) for $30 \mathrm{~min}$ at room temperature and stained with a DAB solution (Dako Cytomation). After counterstaining with a hematoxylin solution, they were mounted in Entellan (Merk, Dermstadt, Germany) and observed under an optical microscope (Olympus, Tokyo, Japan). Fetal vascular systems were distinguished from the maternal blood space by erythrocytes with the nuclear and cellular morphology of vascular endothelial walls.

\section{Statistical analysis}

Statistical analyses were carried out by ANOVA using the $t$-test. Differences of $\mathrm{P}<0.05$ were considered statistically significant.

\section{Results and Discussion}

GPRC5B and RAR $\alpha$ mRNAs were detected in the placenta (Fig. 1A-C) and yolk sac (Fig. 1D-F) on each day of gestation investigated. No significant change in the mRNA level of GPRC5B or RAR $\alpha$ in the placenta or yolk sac was noted during the gestation (13.5, 15.5 and 17.5 dpc; Fig. 1B, C, E and F, respectively). Interestingly, GPRC5B mRNA expression in the glycogen cells (GlCs) and stromal cells (SCs) of the placenta rapidly decreased at 18.5 $\mathrm{dpc}$ [11], indicating GPRC5B may play important roles in parturition.

In the placenta at 13.5 and $15.5 \mathrm{dpc}$, strong staining for GPRC5B protein was detected in maternal vascular endothelial cells (MECs), GlCs, labyrinthine vascular endothelial cells (LECs) derived from the fetus and SCs (Fig. 2A-D, M and O, respectively), but no positive staining was found in the trophoblast cells of the labyrinthine layer. However, no positive staining was detected in the LECs and MECs of the placenta at $17.5 \mathrm{dpc}$ (Fig. 2E, $F$ and $Q$, respectively). No remarkable changes in the intensity of straining for GPRC5B protein in GlCs and SCs were found during the gestation period (Fig. 2E, F and Q, respectively).

In the placenta, weak staining for RAR $\alpha$ protein was found in the nuclear areas of most trophoblast lineage cells, but not GlCs, on each day of gestation investigated. Strong staining was demonstrated in 
A

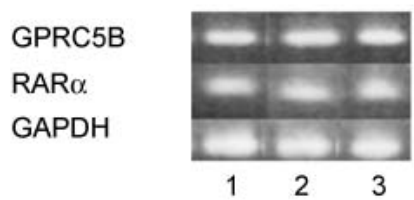

B

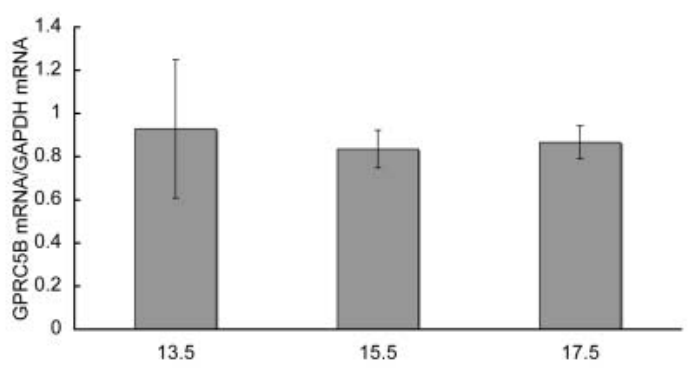

C

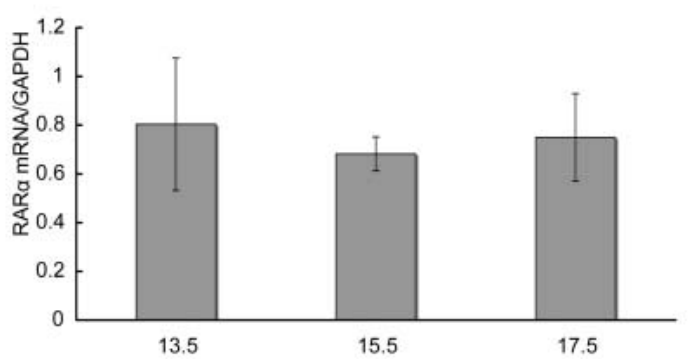

D

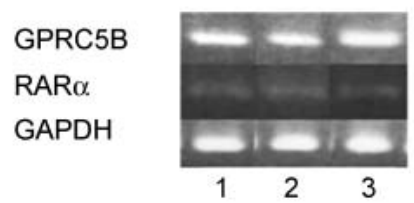

E

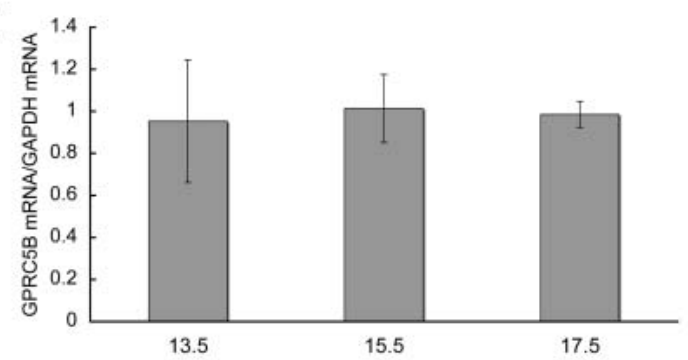

$\mathbf{F}$

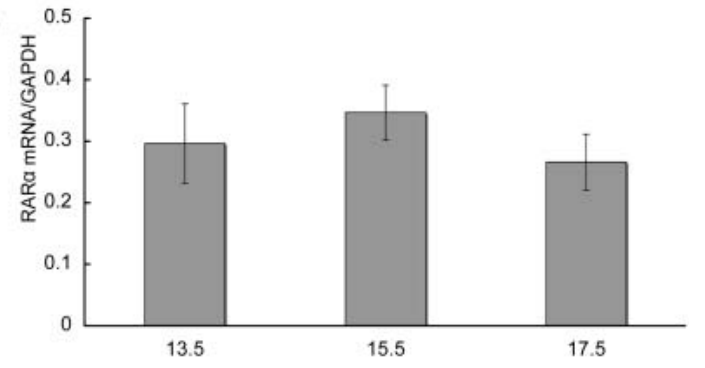

Fig. 1. Representative photographs of the PCR products for GPRC5B, RAR $\alpha$ and GAPDH mRNAs in the placenta (A) and yolk sak (B) at 13.5, 15.5 and $17.5 \mathrm{dpc}$ (lanes 1, 2 and 3, respectively). The relative levels of GPRC5B (B and E) and RAR $\alpha(C$ and F) mRNAs were normalized to the GAPDH mRNA level.

the cytoplasmic areas of MECs, LECs and SCs, which were located in the placenta at 13.5 and 15.5 dpc (Fig. 2G-J, N and P, respectively), but no staining was detected in MECs or LECs at $17.5 \mathrm{dpc}$ (Fig. $2 \mathrm{~K}$, L or R). No remarkable change in staining intensity of RAR $\alpha$ protein was noted in SCs. This expression pattern of RAR $\alpha$ protein was similar to that of GPRC5B protein in the placental labyrinthine layer. Because GPRC5B expression is regulated by RA [2,3], the expression of RAR $\alpha$ protein, a RA receptor, is synchronized with that of GPRC5B protein.

In the yolk sac, strong staining reactions for GPRC5B and RAR $\alpha$ proteins were detected in vascular endothelial cells and the visceral mesoderm (Fig. 2S-X), but no notable change in staining intensity was observed during gestation. $R A R \alpha$ mRNA was also detected in placental and yolk sac tissues by in situ hybridization from 13.5 to $17.5 \mathrm{dpc}$ [21].

Because nutrients and gases are exchanged through trophoblast layers, placental vascular for- mation is essential for maintenance of pregnancy and embryonic development. RA is considered to play critical roles in hematogenesis, vasculogenesis and angiogenesis in the placenta and yolk sac [2224]. Abnormal vasculogenesis and angiogenesis have been described for Raldh $2^{-/-}$mice, which lack the ability to synthesize RA [22, 24]. However, when these animals received RA, they exhibited normal vasculogenesis and angiogenesis. In vitro studies using Flk ${ }^{+}$cells (progenitors of vascular endothelial cells) derived from mouse embryonic stem cells and human umbilical vein cells (HUVECs) have shown that angiopoietin/Tie2dependent formation of blood vessels is regulated by RA [23]. The amount of GPRC5B in vascular endothelial cells may correlate with RA-dependent angiogenesis. GPRC5B expression is also induced by cytokines, TNF $\alpha$ and TGF $\beta 1[13,14]$. No remarkable change in the level of GPRC5B protein was noted in these stromal cells during the gestation period. Stromal cells support the umbilical 

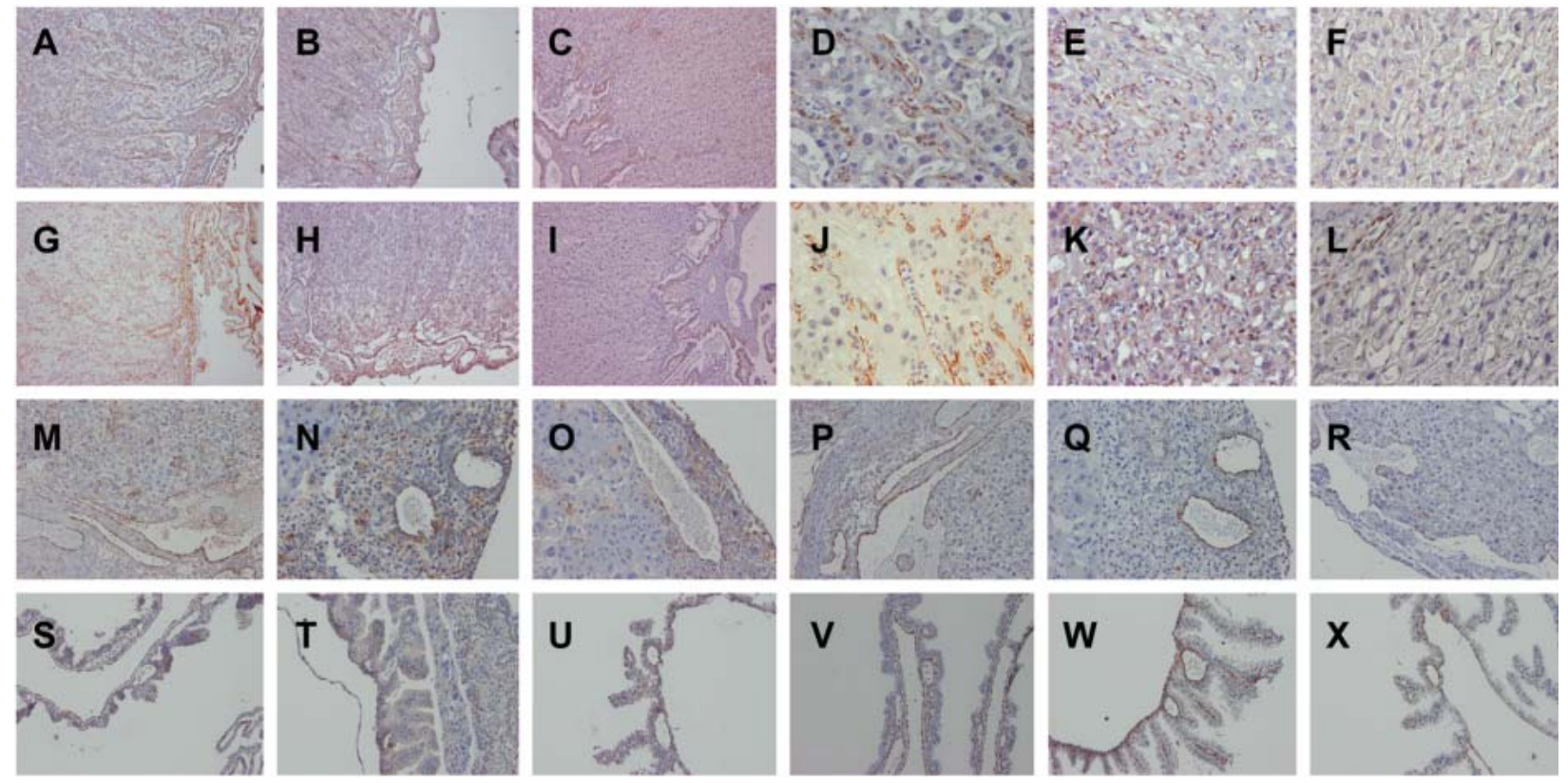

Fig. 2. Representative photographs of immunohistochemical staining for GPRC5B in the labyrinthine layer of the placenta at 13.5 ( $\mathrm{A}$ and $\mathrm{B}), 15.5$ (C and D) and 17.5 (E and F) dpc. Positive staining was detected in the labyrinthine vascular endothelial cells (LECs) of the placenta at 13.5 and $15.5 \mathrm{dpc}$, but not at $17.5 \mathrm{dpc}$. Photographs of immunohistochemical staining for RAR $\alpha$ in the labyrinthine layer at $13.5(\mathrm{G}$ and H), 15.5 (I and J) and 17.5 (K and L) dpc. Positive staining was detected in the LECs of the placenta at 13.5 and $15.5 \mathrm{dpc}$, but not at $17.5 \mathrm{dpc}$. Photographs of immunohistochemical staining for GPRC5B and RAR $\alpha$ in the junctional zone at $13.5(\mathrm{M}$ and N), $15.5(\mathrm{O}$ and $\mathrm{P})$ and $17.5(\mathrm{Q}$ and $\mathrm{R})$ dpc. Positive staining was detected in maternal vascular endothelial cells (MECs) and glycogen cells (GICs). Photographs of immunohistochemical staining for GPRC5B and RAR $\alpha$ in the yolk sac at 13.5 (S and T), 15.5 (U and V) and 17.5 (W and X) dpc. Positive staining was detected in vascular endothelial cells only on all gestation days investigated. A, C, E, G, I, K, M, O, Q, S, U and W: $\times 100$. B, D, F, H, J, L, N, P, R, T, V and X: $\times 400$.

cord and blood vessels in placental tissues. Thus, further study to reveal the interactions among GPRC5B, RA, TGF $\beta 1$ and TNF $\alpha$ in placental hematogenesis, vasculogenesis and angiogenesis is necessary.

Based on the results of the present immunohistochemical analysis, we conclude that GPRC5B, a RAIG family orphan receptor, is regulated by RA and is involved in vasculogenesis and angiogenesis in the placenta and yolk sac.

\section{Acknowledgements}

The Authors are grateful to Y. Kirihata, I. Murai, A. Takasu and T. Kawarabayashi. This study was supported by a Grant-in Aid for Research Fellows of the Japan Society for the Promotion of Science (JSPS) to S. I., a Grant-in-Aid for Creative Scientific Research (13GS0008) to N. M. from the Ministry of Education, Culture, Sports, Science and Technology of Japan and by Grants-in-Aid for Scientific Research (Exploratory Research 18658105, B18380164, S16108003 and S18108004) to N. M. from JSPS.

\section{References}

1. Howard AD, McAllister G, Feighner SD, Liu Q, Nargund RP, Van der Ploeg LHT, Patchett AA. Orphan G-protein-coupled receptors and natural ligand discovery. Trends Pharmacol Sci 2001; 22: 132-
140.

2. Bräuner-Osborne $\mathbf{H}, \quad$ Krogsgaard-Larsen $P$. Sequence and expression pattern of a novel human orphan G-protein-coupled receptor, GPRC5B: a 
family $C$ receptor with a short amino-terminal domain. Genomics 2000; 65: 1121-1128.

3. Robbins MJ, Michalovich D, Hill J, Calver AR, Medhurst AD, Gloger I, Sims M, Middlemiss DN, Pangalos MN. Molecular cloning and characterization of two novel retinoic acid-inducible orphan Gprotein-coupled receptors (GPRC5B and GPRC5C). Genomics 2000; 67: 8-18.

4. Hart AC, Kramer H, Van Vactor DL, Paidhungat Jr M, Zipursky SL. Induction of cell fate in the Drosophila retina: the bride of sevenless protein is predicted to contain a large extracellular domain and seven transmembrane segments. Gene Dev 1990; 4: 1835-1847.

5. Bräuner-Osborne $\mathbf{H}$, Jensen AA, Sheppard PO, Brodin B, Krogsgaard-Larsen P, O'Hara P. Cloning and characterization of a human orphan family C Gprotein coupled receptor GPRC5D. Biochim Biophys Acta 2001; 1518: 237-248.

6. Pin J-P, Galvez T, Prézeau L. Evolution, structure and activation mechanism of family 3/C G-proteincoupled receptors. Pharmacol Ther 2003; 98: 325-354.

7. Cheng Y, Lotan R. Molecular cloning and characterization of a novel retinoic acid-inducible gene that encodes a putative $\mathrm{G}$ protein-coupled receptor. J Biol Chem 1998; 273: 35008-35015.

8. Inoue $\mathbf{S}, \mathbf{N a m b u} T$, Shimomura T. The RAIG family member, GPRC5D, is associated with hard-keratinized structures. Invest Dermatol 2004; 122: 565-573.

9. Clagett-Dame M, DeLuca HF. The role of vitamin A in mammalian reproduction and embryonic development. Annu Rev Nutr 2002; 22: 347-381.

10. Villarroya F, Iglesias R, Giralt M. Retinoids and retinoid receptors in the control of energy balance: novel pharmacological strategies in obesity and diabetes. Curr Med Chem 2004; 11: 795-805.

11. Imanishi S, Manabe N, Tanaka T, Okamoto $\mathbf{R}$, Morita M, Sugimoto M, Miyamoto $\mathbf{H}$. mRNA of GPRC5B/Raig2, a novel orphan receptor, expresses in murine placentae. J Reprod Dev 2002; 48: 627-632.

12. Nagasaka T, Boulday G, Fraser CC, Coupel S, Coulon F, Tesson L, Heslan JM, Soulillou JP, Charreau B. Rapid selection of differentially expressed genes in TNF $\alpha$-activated endothelial cells. Mol Med 2002; 8: 559-567.

13. Tagliafico E, Brunelli S, Bergamaschi A, De Angelis L, Scardigli R, Galli D, Battini R, Bianco P, Ferrari S, Cossu G, Ferrari S. TGF $\beta /$ BMP activate the smooth muscle/bone differentiation programs in mesoangioblasts. J Cell Sci 2004; 117: 4377-4388.

14. Xu J, Tian J, Shapiro SD. Normal lung development in RAIG1-deficient mice despite unique lung epithelium-specific expression. Am J Respir Cell Mol Biol 2005; 32: 381-387.

15. Nagahata $T$, Sato $T$, Tomura A, Onda $M$, Nishikawa K, Emi M. Identification of RAI3 as a therapeutic target for breast cancer. Endocr Relat Cancer 2005; 12: 65-73.

16. Fredriksson $R$, Lagerstrom MC, Lundin LG, Schioth HB. The G-protein-coupled receptors in the human genome form five main families. Phylogenetic analysis, paralogon groups, and fingerprints. Mol Pharmacol 2003; 63: 1256-1272.

17. Krämer H, Cagan RL, Zipursky SL. Interaction of bride of sevenless membrane-bound ligand and the sevenless tyrosine-kinase receptor. Nature 1991; 352: 207-212.

18. Metpally RP, Sowdhamini R. Cross genome phylogenetic analysis of human and Drosophila G proteincoupled receptors: application to functional annotation of orphan receptors. BMC Genom 2005; 6: 106111.

19. Morris I, Williams R. Research strategies for orphan G protein-coupled receptors. Drug News Perspect 2002; 15: 249-252.

20. Bastien J, Rochette-Egly C. Nuclear retinoid receptors and the transcription of retinoid-target genes. Gene 2004; 328: 1-16.

21. Sapin V, Ward SJ, Bronner S, Chambon P, Dolle P. Differential expression of transcripts encoding retinoid binding proteins and retinoic acid receptors during placentation of the mouse. Dev Dyn 1997; 208: 199-210.

22. Bohnsack BL, Lai L, Dolle P, Hirschi KK. Signaling hierarchy downstream of retinoic acid that independently regulates vascular remodeling and endothelial cell proliferation. Genes Dev 2004; 18: 1345-1358.

23. Suzuki Y, Komi Y, Ashino H, Yamashita J, Inoue J, Yoshiki A, Eichmann A, Amanuma H, Kojima S. Retinoic acid controls blood vessel formation by modulating endothelial and mural cell interaction via suppression of Tie2 signaling in vascular progenitor cells. Blood 2004; 104: 166-169.

24. Lai L, Bohnsack BL, Niederreither K, Hirschi KK. Retinoic acid regulates endothelial cell proliferation during vasculogenesis. Development 2003; 130: 64656474. 